\title{
La interacción entre los niños del tercer ciclo de EBR para el fortalecimiento de la convivencia en el aula de un colegio ubicado en Ventanilla, Callao
}

\author{
REYNA PRADO HERRERA* \\ Pontificia Universidad Católica del Perú (PUCP) - Perú \\ MARÍA SÁNCHEZ TRUJILLO** \\ Pontificia Universidad Católica del Perú (PUCP) - Perú \\ Recibido el 21-02-20; primera evaluación el 14-06-21; \\ segunda evaluación el 20-08-21; aceptado el 27-08-21
}

\section{RESUMEN}

El objetivo de esta investigación fue analizar los modos de socialización de los estudiantes de primer y segundo grado de primaria de una institución educativa para una convivencia armoniosa. El estudio es de naturaleza mixta, descriptiva y no experimental. La recolección de la información se realizó considerando tres categorías: modos de interacción, tipos de juegos de los estudiantes, y los conflictos comunes a través de las técnicas de la observación, entrevista y encuesta. A partir del análisis de los hallazgos, se identificó que la interacción entre los estudiantes es principalmente agresiva; los tipos de juego más comunes son las «chapadas», peleas y echarse uno debajo del otro, la mayoría de los cuales incluyen actos de violencia; y los conflictos más recurrentes conducen a situaciones de golpear y empujar.

Palabras clave: interacción entre los estudiantes, juego, convivencia armoniosa.

\footnotetext{
* Estudiante de noveno ciclo de la carrera de Educación Primaria de la Pontificia Universidad Católica del Perú. Docente en formación de la Pontificia Universidad Católica del Perú, Perú. https://orcid.org/0000-0001-5005-9156. Correo electrónico: reyna.prado@pucp.edu.pe

** Doctora en Ciencias de la Educación por la Pontificia Universidad Católica del Perú (PUCP). Magíster en Educación con dos menciones: Trastornos de la Comunicación y Gestión Educativa. Licenciada en Educación en la especialidad de Lengua y Literatura. Asesora pedagógica de diversas instituciones privadas de Lima. https://orcid.org/0000-0002-5228-4688. Correo electrónico: msanchezt@pucp.edu.pe
} 
Interaction between children in the third cycle of EBR to strengthen coexistence in the classroom of a school located in Ventanilla, Callao

\section{Abstract}

The objective of this research was to analyze the modes of socialization of first and second grade students of an educational institution for a harmonious coexistence. The study is of a mixed, descriptive and non-experimental nature. The information collection was carried out considering three categories: modes of interaction, types of student games, and common conflicts through the techniques of observation, interview and survey. From the analysis of the findings, it was identified that the interaction between the students is mainly aggressive; the most common types of play are "chapadas", fights and lying one under the other, most of which include acts of violence; and more recurrent conflicts lead to hitting and shoving situations.

Keywords: interaction between students, play, harmonious coexistence.

\section{Interação entre crianças do terceiro ciclo da EBR para fortalecer a convivência em sala de aula de uma escola localizada em Ventanilla, Callao}

\section{RESUMO}

O objetivo desta pesquisa foi analisar os modos de socialização de alunos de primeiro e segundo anos de uma instituição de ensino para uma convivência harmoniosa. O estudo é de natureza mista, descritiva e não experimental. A coleta de informações foi realizada considerando três categorias: modos de interaçáo, tipos de jogos dos alunos e conflitos comuns por meio das técnicas de observação, entrevista e levantamento. A partir da análise dos achados, identificou-se que a interação entre os alunos é principalmente agressiva; as brincadeiras mais comuns são as chapadas, brigas e deitar umas embaixo das outras, muitas das quais incluem atos de violência; e conflitos mais recorrentes levam a situaçóes de agressão e empurróes.

Palavras-chave: interação entre alunos, brincadeira, convivência harmoniosa.

\section{INTRODUCCIÓN}

La escuela es reconocida como un espacio de socialización; cumple la función formativa de conocimientos, habilidades, actitudes y valores, pero también es el lugar en el cual se reproducen las creencias y costumbres de las personas. Según Crespillo (2010), el rol de la escuela es el de formar futuros ciudadanos a través de la transmisión de aprendizajes y valores que les permitirán aportar significativamente a la sociedad, además de beneficiarse en su desarrollo personal. Asimismo, en la escuela, se producen intercambios humanos intencionados para el logro de la construcción de la identidad de los sujetos. 
Entonces, en la escuela, mediante la socialización, los estudiantes construyen su personalidad (comportamiento), algunos de forma pasiva, mientras que otros de manera asertiva o agresiva. Este conjunto de interacciones influye en la convivencia escolar.

Según Fierro-Evans y Carbajal-Padilla (2019), la noción de convivencia escolar está directamente relacionada con la idea de "aprender a vivir juntos", propuesto en el informe de Delors (1996). Este aprendizaje es precisamente uno de los pilares básicos del aprendizaje e implica la necesidad de generar vínculos duraderos y armoniosos entre los miembros de una comunidad escolar. Para ello, resulta necesaria la aplicación efectiva de estrategias pedagógicas y de gestión. Es evidente que una convivencia armoniosa en la institución educativa favorece la formación integral de los estudiantes y, por ende, contribuye a que sean ciudadanos ejemplares.

A partir de lo anterior, resulta fundamental estudiar cómo se produce la convivencia escolar desde los primeros grados de primaria. Es innegable que la calidad de las interacciones favorece o desfavorece el aprendizaje de los estudiantes. Así, si desea lograr aprendizajes significativos en ellos, es preciso fomentar el desarrollo de una convivencia armoniosa en el aula. De esta manera, si se puede describir a profundidad el modo como los estudiantes de una institución educativa interactúan, es posible proponer medidas efectivas orientadas a eliminar las posibles situaciones conflictivas que los estudiantes podrían enfrentar.

Asimismo, se presenta el problema de investigación mediante la siguiente pregunta: ¿De qué manera los estudiantes de primer y segundo grado de primaria interactúan para una convivencia armoniosa en un colegio privado del distrito de Ventanilla, Callao?

En concreto, el objetivo general de esta investigación es analizar los modos de socialización de los estudiantes para una convivencia armoniosa de primer y segundo grado de primaria. Asimismo, sus objetivos específicos son los siguientes: en primer lugar, se busca describir de qué manera interactúan los estudiantes; en segundo lugar, se pretende describir los tipos de juegos que realizan los estudiantes en el aula y patio; y, finalmente, este estudio se orienta a identificar las formas comunes de conflictos entre estudiantes.

\section{Marco teórico}

La convivencia armoniosa en la escuela es muy importante, porque la interacción entre los estudiantes repercute significativamente en el proceso de la construcción de aprendizajes y en su desarrollo personal. Según Espinoza, 
Ojeda, Pinillo y Segura (2010), la convivencia escolar es «un proceso complejo y dinámico muy difícil de predecir en donde está inserta una serie de variables de comportamiento, y condiciones micro y macro que determinarán su funcionamiento» (p. 23). Entonces, se entiende, por convivencia, la capacidad de las personas de coexistir con otras de manera pacífica, respetuosa y solidaria. Asimismo, implica "interactuar con otros en armonía, con respeto a las ideas y sentimientos de los demás, la tolerancia frente a las diferencias, la aceptación y valoración de la diversidad, la solidaridad, reciprocidad y cooperación mutua en función de objetivos comunes" (Sandoval, 2014, p. 160). En otras palabras, la convivencia escolar implica coexistir de forma tranquila y respetuosa entre los estudiantes y profesores. Entonces, tomando en cuenta los autores antes mencionados, es posible afirmar que la convivencia escolar es la acción de vivir de forma pacífica en una institución educativa con otros agentes educativos (estudiantes, profesores, director, entre otros).

«Las relaciones entre los iguales desempeńan un papel primordial en el desarrollo social infantil» (De la Corte, 2017, p. 32). En efecto, cuando los niños interactúan con sus pares, van fortaleciendo sus habilidades sociales, lo que implica también su desarrollo a nivel emocional y de lenguaje. Por ejemplo, en el primer caso, los niños, cuando se relacionan entre sí, involucran sus emociones. Es decir, dependiendo de cómo se relacionan, se sentirán felices, tristes, enojados, entre otras posibilidades. Con respecto al lenguaje, los niños, cuando se interrelacionan, involucran el habla y ello genera un incremento de su bagaje léxico. Adicionalmente, las interacciones se encuentran directamente vinculadas con la personalidad de los individuos, lo cual permite el fortalecimiento de su autoconcepto o autoestima.

A continuación, se desarrollarán tres aspectos claves directamente vinculados con la noción de convivencia escolar en los primeros grados de educación primaria: los modos de interacción entre los estudiantes, el juego en la infancia y los conflictos entre los nińos.

\subsection{Modos de interacción entre los estudiantes}

Los modos de interacción entre los estudiantes, según Dodge (1986), como se cita en Ortega (2015), pueden ser positivos, agresivos o pasivos. En primer lugar, los positivos o competentes son aquellos en los que el niño actúa de forma autónoma, no agrede ni produce ningún dańo al otro, y utiliza el diálogo como medio de resolución de conflictos. En estos casos, se evidencia un adecuado uso de habilidades sociales del niño o niña, y este demuestra que sabe cómo actuar frente a su interlocutor, pese a posibles desavenencias; 
es decir, es una persona asertiva. En segundo lugar, los modos agresivos de interacción son aquellos que implican alguna conducta violenta al otro, ya sea de forma verbal o física. Es indudable que este tipo de acciones no debe ser utilizado por las personas, ya que, en muchas ocasiones, generan algún tipo de daño. Por último, los modos pasivos se producen cuando el niño o la niña no actúan ante una situación problemática. Ante este tipo de circunstancias, lloran sin recurrir a nadie ni pedir ayuda. Asimismo, se pueden quedar callados ante eventos que generen dańos hacia su persona (o hacia otra), ya sea de manera física o psicológica. En los últimos años, este aspecto ha sido objeto de algunos estudios. Resulta relevante los resultados de la investigación de naturaleza cuantitativa realizada por Ortega (2015) en Madrid, quien identificó que las nińas utilizan una mayor frecuencia de modos positivos de interacción, mientras que los niños utilizan estrategias de tipo agresivo.

Según el Ministerio de Educación (2016), los niños suelen mostrar bastante interés en establecer interacciones con sus pares, así como contribuir de manera activa en su contexto inmediato. También, se caracterizan por lograr la distinción entre las conductas aceptables y las no aceptables, propias de su cultura. No obstante, su interpretación se basa en los efectos concretos de sus acciones, sean estos físicos o afectivos. Conocer esto resulta primordial, pues, como es evidente, los niños aún no han alcanzado un máximo desarrollo moral que les permita diferenciar lo bueno y lo malo sobre la base de reglas sociales que transcienden el premio o el castigo, sino que, más bien, permiten regular la convivencia en la sociedad. En todo caso, a lo largo de su formación, los nińos desarrollan estrategias de autorregulación de sus emociones y de resolución de conflictos con sus pares.

Resulta necesario señalar el enfoque teórico propuesto por Ludwig, Mühlhäusler y Pagel (2016), quienes explican que los modos de interacción deben atender a un modelo tripartito de niveles. El micro nivel se refiere a las características del contexto concreto en donde se produce la interacción. En este caso, tanto aspectos situaciones como meramente lingüísticos cobran especial relevancia. El meso nivel es el espacio urbano en donde se producen las interacciones. Finalmente, el macro nivel está compuesto de los acontecimientos histórico-geográficos que influyen en las relaciones entre los individuos, las cuales, indudablemente, tienen un trasfondo sociocultural.

\subsection{El juego en la infancia}

Según De la Corte (2017), «la interacción entre iguales, especialmente en las primeras etapas evolutivas, consiste principalmente en el juego, y permite 
a los niños ampliar las habilidades sociales, cognitivas y lingüísticas» (p. 31). Entonces, es posible afirmar que los niños interactúan con mayor facilidad cuando se encuentran jugando, puesto que es más fácil relacionarse con los otros. Según la autora antes mencionada, en los primeros ańos de aprendizaje social, el juego es concebido como una actividad de disfrute y de interacción afectiva con los demás. Ahora bien, es preciso mencionar que, aunque los niños pueden interactuar mejor cuando se encuentran en situaciones de juego, algunas de estas involucran la violencia, lo cual se opone a la función primordial del juego en la infancia.

Campos, Chacc y Gálvez (2006) clasifican el juego de acuerdo con el nivel de interacción producido entre los involucrados. En primer lugar, el juego solitario se efectúa cuando el niño juega solo y su interés se focaliza en la actividad lúdica que está realizando más allá de establecer interacciones con sus pares. En segundo lugar, el juego de espectador se produce cuando el niño prefiere disponer de su tiempo de juego observando cómo juegan sus pares. En tercer lugar, el juego paralelo se realiza cuando el niño se localiza en el mismo espacio que sus pares; no obstante, realiza su actividad de manera solitaria. Incluso, puede compartir material con los demás sin establecer ningún tipo de interacción orientada al juego con ellos. En cuarto lugar, el juego asociativo implica el desarrollo de una actividad lúdica en conjunto; no obstante, carece de una organización previa, así como de distribución de responsabilidades. Por último, en el juego cooperativo, el niño juega con los demás de modo organizado, por lo cual existe una repartición prevista de tareas, considerando las metas propuestas.

Por otro lado, Bondioli (1996) afirma que existe un tipo de juego, el simbólico, que resulta sumamente importante en el desarrollo de los nińos. El juego simbólico permite crear nuevos contextos ante los cuales se interpreta la realidad de una determinada forma. Tal interpretación implica planificar un conjunto de acciones para anticiparse a una problemática o solucionarla. En este caso, la importancia no radica en el resultado final del juego, sino en el proceso mismo, el cual es generador de placer y diversión en el niño. Este tipo de juego podría ejecutarse de forma individual o grupal, y facilitar el desarrollo cognitivo de los niños.

En relación con el juego, resulta necesario aludir al estudio efectuado en Costa Rica por Cháves en 2013. La investigación se diseñó sobre la base de una metodología mixta. Entre los resultados, se concluyó que al 42\% de los niños les gusta jugar en el recreo. Los juegos más comunes son anda, congelados y escondidos. Asimismo, se comprobó el temor que sienten algunos nińos de ser golpeados por sus pares, así como por las peleas que observan en el patio. 


\subsection{Los conflictos entre los nińos}

Aunque el juego es una actividad que, idealmente, debe permitir interacciones pacíficas entre los involucrados no siempre es así. En general, todo tipo de interacción es susceptible a la ocurrencia de algún conflicto. El conflicto puede definirse como «el proceso que se inicia cuando una parte percibe que otra la ha afectado de manera negativa o que está a punto de afectar, de manera negativa, alguno de sus intereses» (Espinoza et al., 2010, p. 17). Asimismo, Aron, como se cita en el Ministerio de Educación (2013) menciona que el conflicto es una oposición entre grupos e individuos por la posesión de bienes escasos o la realización de intereses incompatibles El conflicto es un elemento inherente a la naturaleza humana, que opera como motor del desarrollo a lo largo de todo el ciclo vital del hombre. Es decir, este forma parte de la vida de las personas. Además, puede ser orientado hacia una intervención intermediaria entre pares con el fin de acordar una solución en la que ambas partes se vean beneficiadas (Carrillo-Pérez, 2016).

Los conflictos, según Filella, Ross-Morente, Rueda, Solano y Minguella (2016), se pueden generar de dos maneras. Por un lado, la agresión verbal es insultar y reírse del otro (ridiculizar), hablar mal del otro, criticar, amenazar, insultar, entre otros. Por otro lado, la agresión física se produce de dos formas. Por un lado, implica una agresión directa, que es pegar, empujar, entre otros. Por otro lado, involucra una agresión indirecta, que es romper, esconder o robar cosas, entre otros.

Por otro lado, Luján (2015) clasifica los conflictos en interpersonales e interaccionales. Mientras los primeros son los que se producen por intereses opuestos o por posibles amenazas a las expectativas personales, los segundos se desprenden de la interacción entre las personas. Además, este tipo de conflictos, a su vez, pueden ser personales, basados en errores de comunicación o necesidades psicológicas de los involucrados; intragrupales, producidos en un grupo, debido a falta de acuerdo en valores, diferencias socioeconómicas o divergencias de poder; o intergrupales, producidos entre distintos grupos de personas, debido a continuas discrepancias entre sí.

A partir de la información expuesta previamente, es preciso analizar los modos de socialización de los niños desde los primeros ańos de vida. Se podrá realizar tal indagación atendiendo a las formas de interacción que se establecen entre ellos, los tipos de juego que realizan y las formas comunes de conflictos que enfrentan. 


\section{Metodología}

El presente estudio fue realizado entre los meses de agosto y diciembre de 2019. La metodología de la investigación obedece a un enfoque mixto, ya que se ha empleado los dos enfoques de investigación (cualitativo y cuantitativo). Según Ruíz, Borboa y Rodríguez (2013), el enfoque mixto es «un proceso que recolecta, analiza y vincula datos cuantitativos y cualitativos en un mismo estudio o una serie de investigaciones para responder a un planteamiento» (p. 11). En otras palabras, esta metodología implica recolectar, analizar y vincular datos cuantitativos y cualitativos. Asimismo, emplea diversos tipos de técnicas e instrumentos de investigación.

El alcance de la investigación es descriptivo, ya que busca especificar las características de las interacciones establecidas entre los estudiantes. En otras palabras, se orienta a describir rasgos o funciones del fenómeno. En esta investigación, se especifican las características y perfiles del grupo de estudiantes de primer y segundo grado de primaria de un colegio privado de Ventanilla en relación con el objeto de estudio. Además, el diseño de investigación realizada es no experimental, ya que no se ha manipulado las variables, y se basa fundamentalmente en la observación de la situación en particular tal y como se ha producido para, posteriormente, proceder a su análisis.

En esta investigación, se están considerando tres categorías, las cuales son los modos de interacción entre los estudiantes; los tipos de juegos; y los conflictos comunes en el aula y patio. Por ello, a fin de recolectar información directa sobre las categorías antes mencionadas, se consideraron como técnicas pertinentes la observación, la entrevista y la encuesta. En primer lugar, la técnica de la observación brindó a los investigadores el espacio de identificar el lenguaje verbal y no verbal de los observados. Además, como seńala Bernal (2010), es un procedimiento riguroso que permite acceder, de forma directa, a la situación estudiada para su posterior descripción y análisis. En esta ocasión, se ha aplicado la observación no participante. Los instrumentos que se han utilizado para recolectar la información son el cuaderno de campo y la guía de observación. Ambos instrumentos fueron aplicados una vez a la semana durante siete semanas, tomando en consideración la totalidad de la jornada escolar, tanto en espacios de clase como en los de descanso y recreación.

En segundo lugar, la técnica de la entrevista viabiliza el recojo directo de información y datos, mediante la comunicación oral (diálogo de un tema en específico) entre el entrevistador y el entrevistado. Asimismo, como señala Bisquerra (2009), es una técnica complementaria de los otros procedimientos, lo cual permite un acercamiento más a la realidad, teniendo en cuenta diversas 
perspectivas. En este estudio, se ha realizado una guía de entrevista semiestructurada para recoger información de los profesores. Para esto, se solicitó previamente el consentimiento informado de los docentes involucrados, a quienes se mencionó que se resguardaría su privacidad. Luego de su aceptación, en la sexta semana, se procedió a realizar la entrevista cuando los niños no se encontraban en el colegio (hora de salida).

Por último, la encuesta es una técnica para recoger datos que se realiza a través de un cuestionario dirigido a los niños. Se eligió este instrumento, pues es el que se utiliza con mayor frecuencia para recolectar datos vinculados con fenómenos sociales (Hernández, Fernández y Baptista, 2014). Las preguntas del cuestionario tienen respuestas múltiples, las cuales ayudaron a delimitar mejor las alternativas en función de las categorías planteadas. Para realizar la encuesta antes, se tuvo que pedir permiso a la Directora, quien solicitó previamente la autorización de los padres de familia con el fin de que sus hijos formaran parte del presente estudio.

Los informantes y/o la muestra que brindaron datos para la investigación, mediante las técnicas antes mencionadas, son 4 profesores (profesora de Inglés, maestra de Matemática, la docente de Comunicación, y el profesor de Ciencia y Tecnología); y 14 alumnos: 7 estudiantes de primer grado de primaria (2 mujeres y 5 varones) y 7 estudiantes de segundo grado (3 mujeres y 4 varones). Se eligió a ese grupo de docentes, porque ellos son los agentes principales de la interacción entre los estudiantes que se ha observado en el aula y patio de la institución educativa. Las personas antes mencionadas provienen del distrito de Ventanilla, Callao. Cabe precisar que la institución educativa se ubica en una zona en donde abunda la delincuencia, como manifestaron algunos de los docentes entrevistados.

\section{Resultados}

El análisis de los resultados se llevó a cabo a partir de los datos obtenidos en la observación, entrevistas a los profesores y encuestas aplicadas a los estudiantes, en las cuales se evaluó la interacción y los tipos de juegos de los estudiantes, y los conflictos comunes en el aula y patio. El análisis se realizó a partir de las tres categorías propuestas: modos de interacción, tipos de juego y conflictos entre los estudiantes. A continuación, se brindan los resultados, en los que se utilizaron las iniciales de los y las estudiantes para aludir a algunas acciones importantes que realizaron en las clases y recreos. Asimismo, se tendrá en reserva los nombres de los profesores. 
En primer lugar, el análisis de la información obtenida en la observación, entrevista y encuesta muestra que las formas de interacción entre los estudiantes, tales como positivas o competentes y agresivas, presentan un mayor porcentaje de ocurrencia en los espacios del aula y patio. Además, los modos positivos de interacción se producen en la minoría de los estudiantes (4 de ellos), mientras que el resto suele adoptar una postura pasiva o agresiva. (Figura 1). Algunas de las frases comunes emitidas al respecto por los profesores en la entrevista, las cuales evidencian distintos modos de interacción, son las siguientes: «(...) el niño "I», por sus actitudes es rechazado (...) a veces él rechaza, grita o empuja y por eso lo rechazan, porque no sabe jugar (...)», «(...) los niños piensan lo siguiente como es mi amigo lo puedo golpear», «(...) Es el caso de las niñas del primer grado si son un poquito más unidas con los compañeros, ya que en todo momento juegan juntos (...)»y »La socialización entre pares muchas veces es agradable (...) los niños son más tranquilos, ya que comparten sus cosas (...)». Todo lo anterior ilustra situaciones cotidianas del colegio que dan cuenta de la manera en que actúan los estudiantes entre ellos.

Figura 1. Interacción entre los estudiantes de primer y segundo grado de primaria

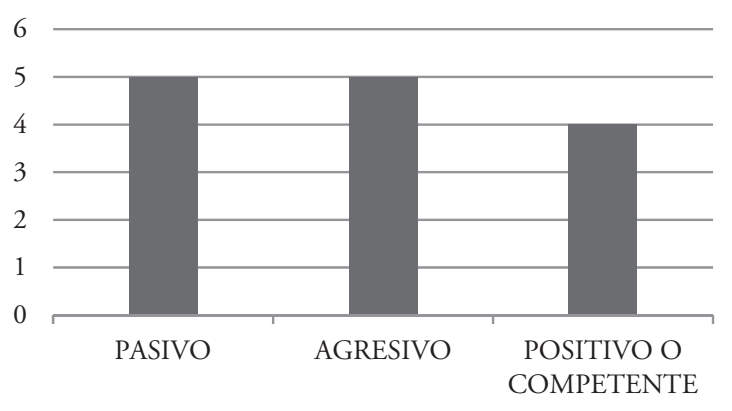

Por un lado, se evidenciaron conductas agresivas de forma física entre los estudiantes en primer y segundo grado de primaria; por ejemplo, el niño «T» tira un borrador al niño «I», porque realizaba mucho ruido; el niño «T» le tira una cachetada a la niña «G»; el niño «I» empuja a la nińa «L»; el niño «R» patea al niño «L»; los niños «I» $\mathrm{y}$ «L» pelean en el recreo; el niño «L» golpea a la niña «G»; y el niño «L» empuja a la niña «A» y al niño «G». En suma, se evidencia que las interacciones entre los niños se caracterizan por las formas de poder en las que predomina la fuerza física; asimismo, la patada, el golpe y el puño son utilizados como recursos de un niño que quiere obtener algo del otro. 
Por otro lado, se observó una interacción agresiva de forma psicológica en los mismos grados. Por ejemplo, el niño «G» ofende a otros con apelativos como «tonto», «narizón» y «orejón»; el niño «T» molesta al niño «I» diciendo que se calle; los nińos del aula de primer grado discuten, porque un niño obtuvo una estrella que no se merecía; el niño "F» se ríe del niño "C», porque no sabe decir «rojo» en inglés; los niños de primer grado dicen al niño "T» que es «pegalón»; el niño «T» le dice al niño «F» «bebé»; el niño «I» le dice a la niña «A» que se calle; el niño «R» amenaza al niño «L»: si sigue hablando, le va a pegar; el niño "L» dice a la nińa "Q" «loca» y ella se pone a llorar, entre otras conductas similares. El análisis de información obtenida muestra que los apodos son la forma importante de descalificación frecuentemente utilizada por los nińos que aparecen a partir de la presencia de alguna característica física que el grupo considera inaceptable, lo cual se explicó anteriormente. Además de ello, es posible afirmar que las formas psicológicas de agresión involucran represiones, situaciones de celos, burlas y amenazas.

Por último, se observaron otras conductas de carácter agresivo, relacionadas también con abusos de poder en los que la víctima asume un rol pasivo. A continuación, se presentan algunos ejemplos. Al niño «T» no le gusta compartir un juguete con los demás; el niño «F» le quita su fruta a la nińa «L», porque ella se la quitó primero; el niño "T» se preocupa por el nińo «F», porque tuvo una caída cuando estaba corriendo; la nińa «G» se cae y todos se ríen; los niños de primer grado comienzan a quitar el gorro del niño «T», pues piensan que es un juego, a pesar de que a "T» no le gusta; las niñas «A» $\mathrm{y}$ "Q $\mathrm{Q}$ " discuten de todo y un niño ayuda a otro a sacar un juguete. Estas conductas de agresión fueron observadas, con mayor intensidad, en segundo grado de primaria.

En segundo lugar, en cuanto a las formas de juegos que realizan los estudiantes, se identificó que el mayor porcentaje observado corresponde a las chapadas, la pelea y echarse uno debajo del otro (Figura 2). Todo lo anterior se evidenció en la observación que se realizó durante las siete semanas que duró el trabajo de campo. Los niños de primer grado juegan a echarse uno debajo del otro y los estudiantes de ambos grados juegan, en el recreo a la pelea y chapadas, lo cual es realizado de forma muy violenta; por ejemplo, con patadas, puñetes, empujones, entre otros. Asimismo, en la entrevista realizada, los profesores mencionaron lo siguiente: «Es frecuente el juego de las peleas, ya que algunos dicen que yo soy Gokú. En este caso, el niño «R» le gusta los Avengers y Bley Bley, las batallas. En ellos es pelea y, más que todo, los videojuegos en casa y eso los que les incita a pelear. En primer grado, igual están con las cartas de Gokú y por esas cartas se pelean, porque quieren las cartas» $\mathrm{y}$ «(...) juegan a las chapadas; ellos ya saben que no deben de tocar, sino empujar (...)». 
Figura 2. Juegos realizados por los estudiantes de primer y segundo grado de primaria

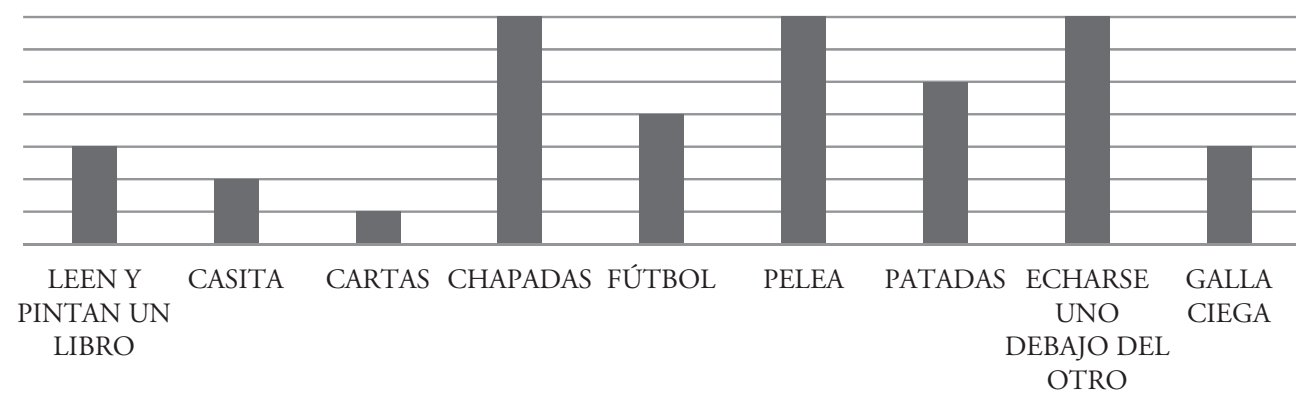

Por otra parte, según lo observado en la hora de recreo, se evidenció que, en muchas ocasiones, los niños y niñas juegan de forma separada (Figura 3). Así, se identificó que los niños juegan en casi todo el patio y las niñas en una de las esquinas del colegio. Las niñas generalmente leen y pintan un libro, juegan a la casita y a las cartas. En cambio, los nińos juegan a las chapadas, fútbol, la pelea y a las patadas. Ahora bien, todos los niños y las niñas de primer grado juegan a la pelea y echarse uno debajo de otro, mientras que los nińos y las nińas de segundo grado juegan a la gallinita ciega.

Figura 3. Juego entre niños y niñas

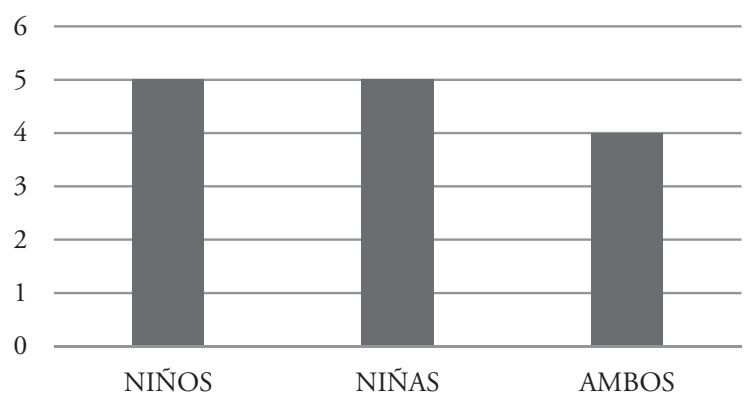

Además de lo anterior, se observó que algunos niños que solían ser burlados por otros preferían jugar de manera individual en una esquina del patio del colegio.

Para finalizar, en cuanto a los conflictos comunes que ocurren dentro y fuera del aula tales como golpear y empujar, ciertas conductas presentan un mayor porcentaje de ocurrencia frente a otras, tales como ridiculizar, criticar, 
amenazar e insultar (Figura 4). Los conflictos se presentan en las diferentes actividades propias de los espacios escolares: el aula y patio. Al respecto, algunas de las respuestas emitidas por las profesoras son las siguientes: «(...) entre ellos se gritan o insultan (...)», «(...) juegan a las chapadas, ellos ya saben que no deben de tocar, sino empujar (...)», «(..) piensan que como es mi amigo lo puedo golpear» $\mathrm{y}$ «Los estudiantes se colocan apodos».

Figura 4. Conflictos entre los estudiantes de primer y segundo grado de primaria

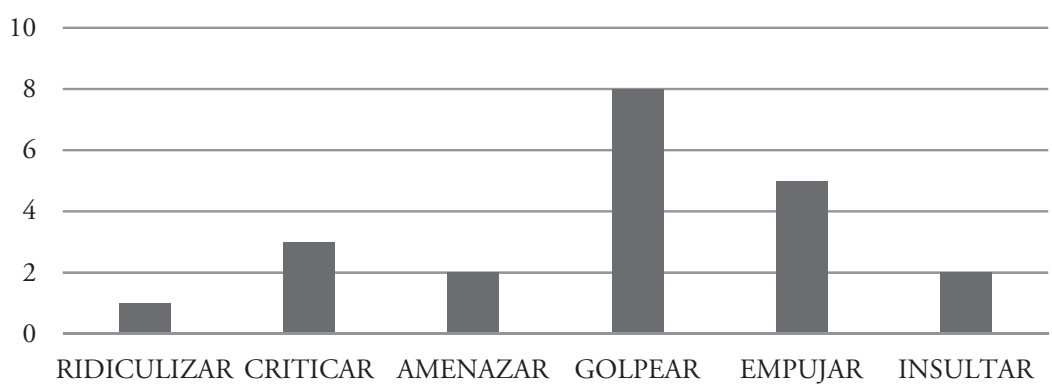

En la encuesta dirigida a los estudiantes, los resultados relevantes respecto de los conflictos ocurridos entre ellos serán explicados a continuación. Por un lado, la mayor parte de los estudiantes se han sentido insultados por sus compańeros de clase (Figura 5). Algunos de ellos, incluso, han naturalizado estas acciones, ya que en los cuestionarios que completaron indicaron, sin pensarlo con detenimiento, que sí habían sido insultados por sus pares. Asimismo, se evidencia que los niños colocan apodos e insultos a sus compañeros sin tener ningún tipo de reconocimiento de culpa.

Figura 5. Niños de primer y segundo grado de primaria que se han sentido insultados

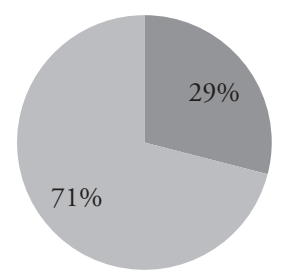

NO INSULTADOS INSULTADOS 
Por otro lado, la mayor parte de los estudiantes han sentido que alguna vez ha sido empujado por sus compañeros de aula (Figura 6). Todo ello ilustra situaciones cotidianas que suceden en las escuelas que dan cuenta de cómo el conflicto es asumido en la interacción como normal por parte de los docentes y estudiantes. En suma, se observa que los conflictos comunes son los relacionados con el abuso físico.

Figura 7. Nińos de primer y segundo grado que han sido empujados por sus pares

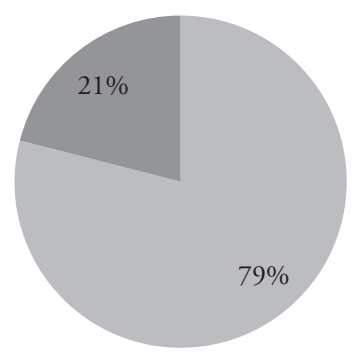

HA SIDO EMPUJADO NO HA SIDO EMPUJADO

Es preciso señalar que las conductas de agresividad física y verbal se manifiestan preferiblemente fuera del aula, ya que, en pocas ocasiones, son observados directamente por los docentes, aunque, como se evidenció en las entrevistas, ellos están totalmente enterados de su ocurrencia. Las acciones son naturalizadas por parte del agresor, agredido y observadores. Por ello, son predominantes en estudiantes que han sido identificados y reconocidos por docentes y pares según los instrumentos aplicados.

\section{Discusión}

Los anteriores resultados dan cuenta de la presencia de violencia física y psicológica en un espacio que debe contribuir a la construcción de personas autónomas, que es la escuela. Esta es considerada como un espacio de socialización, en el cual se involucran las costumbres y se reproducen las creencias de los estudiantes. A partir de los hallazgos resultantes de los instrumentos aplicados, muchos de los alumnos demuestran que la agresión verbal y física es una acción frecuente y naturalizada para interactuar e intercambiar ideas.

La convivencia armoniosa en la escuela es muy importante, porque la interacción entre los estudiantes repercute significativamente en el proceso 
de la construcción de aprendizajes y en su desarrollo personal. Pese a ello, en los hallazgos, se evidenció que, en pocas ocasiones, los estudiantes conviven de forma armoniosa, porque no suelen respetar las ideas de otras personas y comienzan a burlarse de lo que dicen. Por ello, no toman en cuenta las emociones de los demás cuando colocan apodos, realizan bromas, golpean, empujan, entre otros. Esto influye negativamente en una convivencia armoniosa, la cual implica coexistir con otros de manera pacífica, sobre la base de la práctica de valores comunes, tales como el respeto mutuo, la tolerancia y la cooperación (Sandoval, 2014).

Los modos de interacción entre los estudiantes, según Dodge (1986), como se cita en Ortega (2015), pueden ser positivos, agresivos o pasivos. En los hallazgos, si bien se evidenciaron formas positivas de interacción, estas son realizadas con menor frecuencia y, más bien, predominan las pasivas y las agresivas. Asimismo, los docentes han identificado que la mayoría de los estudiantes utilizan estrategias agresivas para relacionarse con los demás. Ellos consideran que los estudiantes del aula de segundo grado de primaria son quienes actúan de forma más violenta en comparación con los que pertenecen al aula de primer grado de primaria. En otras palabras, los profesores ya han identificado quiénes son los estudiantes "problemáticos». Pese a ello, no se observó la aplicación de estrategias didácticas orientadas a mejorar esta situación. Cabe resaltar, además, que son las niñas las que suelen establecer con mayor frecuencia interacciones positivas, lo cual concuerda con el estudio efectuado por Ortega (2015).

En cuanto a las interacciones pasivas, estas se manifestaron cuando, en situaciones de conflicto, los testigos de tales eventos no intervinieron para tratar de ayudar a la víctima. Asimismo, en muchos casos, las víctimas tampoco son capaces de reaccionar ante tales agresiones. Por otro lado, en cuanto a los modos agresivos de interacción, se han evidenciado tanto conductas violentas físicas como psicológicas, realizadas principalmente durante la hora de recreo o en espacios fuera del aula de clase. Tales formas de agresión podrían resultar comprensibles en la medida en que, dada la edad de los niños, estos aún no han alcanzado un desarrollo moral que les permitan diferenciar los actos buenos de los errados (Ministerio de Educación, 2016). A ello, se suma el contexto violento en la que la institución educativa se encuentra inmersa y que podría haber influida en las conductas agresivas que estos estudiantes han adoptado, puesto que, como señalan Ludwig et al. (2016), existen diversos niveles en los que se producen las interacciones y pueden, de algún modo, condicionarlas. Justamente, el meso nivel, referido al espacio local urbano que rodea la interacción, podría haber intervenido en la generación de tales conductas 
violentas. Por otro lado, tomando en consideración la clasificación realizada por Filella et al. (2016), es posible afirmar que las agresiones que se producen con mayor frecuencia son principalmente verbales y físicas directas. Es preciso resaltar, por otra parte, el rol pasivo que cumplen los docentes al normalizar tales situaciones y atribuirlos al modo en que sus estudiantes interactúan sin manifestar acciones que hayan tomado o piensen que se deban tomar para evitar su reiteración.

En relación con las formas de juego de los niños, predominan las que implican contacto físico. Es preciso afirmar que se han observado juegos que han cumplido uno de sus objetivos, en el sentido de que han permitido estrechar vínculos con sus pares (De la Corte, 2017), además de que los estudiantes de primer y segundo grado de primaria se relacionan con mayor facilidad cuando comienzan a jugar en el patio o aula de clases. Sin embargo, la mayoría de los juegos realizados involucran situaciones de agresión, lo cual resulta preocupante, pues pareciera ser que la violencia es un aspecto transversal en todas las formas de interacción de estos niños. En efecto, las peleas son consideradas como juegos, tanto en niños como en docentes. Una vez más, se evidencia la normalización de este tipo de actos por parte de todos los actores inmersos en la institución. Pese a ello, también se pudo evidenciar, en los cuestionarios aplicados, el temor que sienten algunos de los nińos frente a estas situaciones violentas, lo cual concuerda con el estudio desarrollado por Chaves (2013).

Campos et al. (2006) clasifican el juego de la siguiente manera: solitario, paralelo y cooperativo. En primer lugar, el juego solitario se produce cuando el nińo juega solo y se enfoca en la actividad en sí misma. Algunos niños juegan de manera individual en una esquina del colegio, ya que sienten miedo de ser golpeados o no les gusta relacionarse con otros. Esto se evidenció en la observación realizada. En segundo lugar, el juego paralelo se efectúa cuando el niño, a pesar de compartir un mismo espacio con otros nińos, realiza su actividad lúdica de manera independiente. Este tipo de juego se evidenció cuando las niñas y los niños jugaban de manera separada, pero se encontraban en el mismo espacio (patio). Según los resultados, los niños son quienes ocupan el mayor espacio de juego. Por último, el juego cooperativo se produce cuando el niño juega con sus pares, sobre la base de una organización clara y efectiva. De esta forma, se reparten tareas en función de los objetivos a conseguir. Esto se pudo evidenciar cuando los nińos comenzaron a jugar de forma colaborativa a la gallina ciega, las chapadas y echarse uno debajo del otro. Tales juegos se basan en ciertas reglas y pautas que los niños establecían anticipadamente. Por ejemplo, para el juego de la gallina ciega, los nińos de segundo grado se organizaron previamente para determinar quiénes iban a correr y quién sería 
la persona que se cubriera los ojos con una chompa de colegio. La persona que fuera atrapada sería aquella que se debía cubrir los ojos. En el caso del juego de las chapadas, este consideró una regla muy curiosa, ya que los estudiantes determinaron que la persona que colocara su mano en una esquina no podría ser atrapada por otra. Finalmente, en el último juego, los niños de primer grado de primaria se organizaron para determinar la persona que sería aplastada por los demás. Ahora bien, pese a ciertos aspectos positivos que algunos de estos juegos podrían incluir, es necesario resaltar que todos estos se realizaron de manera violenta, ya que se evidenciaron agresiones de forma directa, como golpes, puñetes o empujones. En tal sentido, se puede afirmar que, si bien existió una organización conjunta previa a la realización de los juegos, durante su ejecución, se manifestaron conductas violentas que alteraron el desarrollo normal de estas dinámicas.

En cuanto a los conflictos ocurridos entre los niños, es posible afirmar que estos son plenamente conscientes de su ocurrencia, pues así lo manifestaron en los cuestionarios que completaron; y, en muy pocos casos, son resueltos de forma pacífica y armoniosa. En las observaciones realizadas, se observaron casos de ridiculización, amenazas, críticas, insultos, entre otros, además de las situaciones agresivas físicas, generadas por situaciones de conflicto no solucionadas apropiadamente ni con la mediación de un adulto. Ello se opone la noción de conflicto, la cual debe conducir a una situación en la que las dos partes involucradas lleguen a un acuerdo sin que ello desencadene situaciones de agresión y en donde la figura de un intermediario cobra especial relevancia (Carrillo-Pérez, 2016). Se evidencia, en tales casos, una situación de abuso de poder: es posible identificar con claridad aquellos nińos que suelen estar inmersos en este tipo de actos, ya sea en un rol de víctima o en un rol de victimario. Si bien los conflictos son eventos propios de la naturaleza humana (Ministerio de Educación, 2013), es evidente que tales situaciones están afectando la tranquilidad de los niños y, por ende, una convivencia armoniosa, caracterizada por una coexistencia pacífica, respetuosa y solidaria (Espinoza et al., 2010). Tampoco, los estudiantes estarían valorando la diversidad propia existente entre ellos ni estarían actuando de forma recíproca (Sandoval, 2014). Por último, atendiendo a la clasificación realizada por Luján (2015), los conflictos producidos son interaccionales, principalmente personales o intragrupales.

Para finalizar, es preciso señalar que los conflictos, según Filella et al. (2016), se pueden generar de dos maneras. Por un lado, la agresión verbal que es insultar y reírse del otro (ridiculizar), hablar mal del otro, criticar, amenazar, insultar, entre otros. Según la encuesta realizada, más del 70\% de los estudiantes se han sentido insultados por uno de sus compañeros. Por otro lado, 
la agresión física, que se produce de forma directa, incluye acciones como empujar y golpear, las cuales fueron las más comunes y naturalizadas por los estudiantes, porque, para ellos, resultaba «normal» realizar estas acciones.

En suma, la falta de una convivencia armoniosa evidenciada en estos niños estaría afectando su desarrollo socioemocional, pues, como señala De La Corte (2017), el establecimiento de interacciones positivas permite el fortalecimiento emocional y del lenguaje; caso contrario, las interacciones negativas desfavorecen tales aspectos del desarrollo.

\section{Conclusiones}

A partir de los hallazgos anteriores, es posible afirmar que no se está generando una convivencia armoniosa, pues no hay una coexistencia basada en el respeto mutuo, tolerancia y cooperación. Predominan situaciones de agresión psicológica, especialmente verbal y física, en donde sobresalen la patada, el golpe y el puño. Todo ello, además, es normalizado por los estudiantes y docentes. También, se evidencian modos pasivos de interacción, en donde no hay apoyo a las víctimas de agresión ni reacción por parte de estas.

En cuanto al juego, este no está cumpliendo adecuadamente su función de facilitador de vínculos. Más bien, se realiza principalmente de forma agresiva. Cuando no lo es, ello se debe a que, o bien los niños juegan solos, o bien hay una separación entre grupos de niños y niñas (estas últimas, sobre todo las de segundo grado de primaria, participan en juegos menos agresivos que sus pares varones). En relación con los conflictos, se evidenciaron situaciones de abusos de poder, las cuales se solían tornar en conductas agresivas físicas o psicológicas. De esta manera, las situaciones problemáticas, como es natural, se producen, pero, en su mayor parte, no llegan a ser solucionadas. Tampoco, se evidenció una intervención por parte de algún adulto que permita la resolución efectiva de este tipo de situaciones.

Todo lo anterior influye negativamente en la convivencia armoniosa de los estudiantes, lo cual, a su vez, afecta la percepción de los propios niños, la naturalización de actos de violencia y, a la vez, sentimientos de temor frente a posibles conductas agresivas reiterativas. Tal situación es preocupante, pues podría estar afectando la formación integral de los estudiantes, lo que les impedirá convertirse en ciudadanos íntegros, capaces de convivir de manera exitosa en la sociedad en la que están insertos. 


\section{REFERENCIAS BIBLIOGRÁFICAS}

Bernal, C.A. (2010). Metodología de la investigación (2da. ed.). Santa Fe de Bogotá: Pearson Educación.

Bisquerra, R. (2009). Metodología de la investigación educativa. Madrid: La Muralla S.A.

Bondioli, A. (1996). Gioco e educazione. Bolina: Il Mulino.

Campos, M., Chacc, I. y Gálvez, P. (2006). El juego como estrategia pedagógica: una situación de interacción educativa. (Tesis de licenciatura). Universidad de Chile, Santiago, Chile. Recuperado de http://repositorio.uchile.cl/tesis/ uchile/2006/campos_m/sources/campos_m.pdf

Carrillo-Pérez, R. (2016). Resolución de conflictos: hacia una cultura de paz en niños de primaria. Ra Ximhai, 12(3), 195-205. https://doi.org/10.35197/ rx.12.02.2016.12.rc

Cháves, A. L. (2013). Una mirada a los recreos escolares: El sentir y pensar de los niños y nińas. Revista electrónica Educare, 17(1), 67-87. https://doi. org/10.15359/ree.17-1.4

Crespillo, E. (2010). La escuela como institución educativa. Pedagogía Magna, 5, 257-261. Recuperado de https://dialnet.unirioja.es/servlet/articulo? codigo $=3391527$

De la Corte, C. M. (2017). Relación entre iguales, personalidad y problemas de ajuste en escolares de primaria de Huelva. (Tesis doctoral). Universidad de Huelva, Huelva, España). Recuperado de http://rabida.uhu.es/dspace/bitstream/ handle/10272/15020/Relacion_entre_iguales.pdf?sequence $=2$

Delors, J. (1996). La educación encierra un tesoro. Informe de la UNESCO de la Comisión Internacional sobre la Educación para el Siglo XXI. Madrid: Santillana/UNESCO

Espinoza, I., Ojeda, P., Pinillo, L. y Segura, S. (2010). Convivencia escolar en una escuela básica municipal de la reina. Conocimiento de su manual de convivencia: un estudio de caso. (Tesis de magíster) Universidad Andrés Bello, Santiago, Chile). Recuperado de http://repositorio.unab.cl/xmlui/handle/ $\mathrm{ria} / 15860$

Fierro-Evans, C. y Carbajal-Padilla, P. (2019). Convivencia escolar: una revisión del concepto. Psicoperspectivas. Individuo y Sociedad, 18(1), 1-19. https:// doi.org/10.5027/psicoperspectivas-Vol18-Issue1-fulltext-1486

Filella, G., Ross-Morente, A., Rueda, P., Solano, A. y Minguella, E. (2016). Análisis de conflictos entre iguales en las escuelas de educación primaria. Revista de Educación Social, 23, 301-314. Recuperado de http://www. ub.edu/grop/wp-content/uploads/2014/03/RES.pdf 
Hernández, R., Fernández, C. y Baptista, P. (2014). Metodología de la investigación (6ta. ed.). México: Mc Graw Hill.

Ludwig, R., Mühlhäusler, P. y Pagel, S. (2016). Linguistic ecology and language contact. Cambrigde: Cambridge University Press.

Luján, I. (2015). Mediación y resolución de conflictos. Las Palmas de Gran Canaria: Universidad de Las Palmas de Gran Canaria.

Ministerio de Educación. (2013). Tutoría y orientación educativa. Aprendiendo a resolver conflictos en las instituciones educativas. Lima: Ministerio de Educación del Perú. Recuperado de http://www.minedu.gob.pe/minedu/ archivos/a/002/02-bibliografia-comun-a-ebr-eba-y-etp/7-aprendiendo-aresolver-conflictos-en-las-instituciones-educativas.pdf

Ministerio de Educación. (2016). Programa curricular de Educación Primaria. Lima: Ministerio de Educación del Perú. Recuperado de http://www.minedu. gob.pe/curriculo/pdf/programa-curricular-educacion-primaria.pdf

Ortega, C. (2015). Interacción entre iguales. (Tesis de licenciatura). Universidad de la Rioja, Madrid, España).

Ruíz, M., Borboa, M. y Rodríguez, J. C. (2013). El enfoque mixto de investigación en los estudios fiscales. TLATEMOANI, Revista Académica de Investigación, 13, 1-25. Recuperado de http://www.eumed.net/rev/tlatemoani/13/estudios-fiscales.pdf

Sandoval, M. (2014). Convivencia y clima escolar: claves de la gestión del conocimiento. Última década, 22(41), 153-178. https://doi.org/10.4067/ S0718-22362014000200007 